\title{
The Effect of Presentation Strategy on Reading Comprehension of Iranian Intermediate EFL Learners
}

\author{
Hooshang Khoshsima \\ Faculty of Management and Humanities, Chabahar Maritime University, Chabahar, Iran \\ E-mail: khoshsima@cmu.ac.ir \\ Forouzan Rezaeiantiyar (Corresponding author) \\ Faculty of Management and Humanities, Chabahar Maritime University, Chabahar, Iran \\ E-mail: f.rezaeiantiyar@yahoo.com
}

Doi:10.7575/aiac.alls.v.5n.3p.101

Received: 01/04/2014

URL: http://dx.doi.org/10.7575/aiac.alls.v.5n.3p.101

Accepted: 14/05/2014

\begin{abstract}
The present experimental study primarily aimed at examining the effect of presentation strategy on reading comprehension of Iranian intermediate EFL learners. To determine the effect of this strategy, 61 students who enrolled in English Language Center of Chabahar Maritime University were initially selected and then divided randomly into two classes one as an experimental group and the other one as the control group. The homogeneity of their proficiency level was established via the administration of a TOEFL (the PBT) proficiency test. A reading comprehension test as pre-test administered to the subjects of both groups one week before the initiation of the study. The experimental group used the strategy three sessions each week for ten weeks, while the control group was trained based on the ordinary approaches of teaching reading comprehension. Presentation strategy was worked for every two weeks during the experiment and then at the end of each two-week instruction, an immediate posttest was administered according to the strategy worked. At the end of the study, a post-test was administered to both groups. The statistical techniques being applied were Paired Sample t-test and Independent Sample t-test. The results of the study revealed that presentation strategy had significant effect on promoting reading comprehension of intermediate EFL learners.
\end{abstract}

Keywords: reading strategy, presentation strategy, reading comprehension, EFL learners

\section{Introduction}

Teaching and learning processes have recently undergone so many changes in educational contexts. In this vein, the process of teaching various skills is not an exception. Among all the language skills, reading is the most important one which has always been regarded essential to educational success. Reading, the highly valued second language skill, is realized as the most stable and durable skill among the other ones (Maher Salah, 2008; Jimenez, Garcia, \& Pearson, 1996).

In the area of English as foreign or second reading research, a great number of studies have been carried out on the importance of various components/variables which affect reading comprehension. Reading is an active process in which "The reader interacts with the text to create meaning as the reader's mental processes interact with each other at different levels to make the text meaningful" (Barnett, 1989, p. 29). Comprehending the meaning of texts regarded as the ultimate goal of students. According to Tierney and Readence (2005) reading comprehension is regarded as one of the major goals for ESL/EFL students to achieve an understanding of the world around them and of themselves and encouraging them to hesitate about the contents of what have read. Reading comprehension is a sophisticated cognitive process in which the reader makes meaning by using simultaneously all the accessible resources and information from both the reading passage and background knowledge. These information help readers in using vocabularies and syntax, monitoring their meaning from one's mental storage, making inferences and applying schemata (Alderson, 2000).

The weakness of students to effectively read texts, may be attributed to a variety of reasons including the absence of enough knowledge with the topic and the schemata of Witten massages, inefficacy of language learners' in target language proficiency, and ineffective reading strategy use (Wood, Motz, \& Willoughby, 1998). ESL/EFL readers state that lack of sufficient reading comprehension techniques is regarded as one of the major hindrances to text comprehension. Thus, reading strategy use is an aid to improve poor reading comprehension. Reading strategies are considered useful solutions to handle the challenges of reading comprehension obstacles. Moreillon (2007) argues that reading comprehension strategies are defined as effective tools or plans for accelerating, improving, and widening students' comprehension. Reading comprehension strategies guide students remember the main concerns, differentiate the related and unrelated data, think about the main ideas, receive feedback, and provide remarks on the major discussions of the texts. 
Since 1970s, second language theorists and curriculum developers advocated a wide range of reading strategies to teach $\mathrm{EFL/ESL}$ learners to become skilled readers in the target language. To a large extent, what these researches reveal is that, the threshold for reading comprehension is reading strategy. Proficient readers usually utilize these learning strategies before, during and after reading (Richards \& Renandya, 2002). Those strategies are classified into cognitive, metacognitive, compensation, memory, affective, and social strategies (Chamot \& O'Malley, 1994). Indeed, empirical reading studies attempted to investigate the importance of strategies, utilization of strategies, strategy instruction, and their contribution to students' reading comprehension enhancement (Alsheikh \& Mokhtari, 2011; Lee, 2007; Mokhtari \& Reichard, 2004).

The current research will assist EFL students to improve their reading comprehension ability by using presentation strategy and doing different varieties of activities relevant to this strategy. Moreover, it indicates to some sort of pedagogical value in EFL contexts and make EFL teachers to provide learners with extensive details to apply presentation strategy in reading comprehension. Although there are different strategies and activities for improving students' reading comprehension; the current research has focused on presentation strategy. The primary objective of this study was proposed to probe the effect of presentation strategy on reading comprehension of Iranian Intermediate EFL learners. Presentation strategy is the devise which teachers use to assist their students to be able concisely and briefly present key points of the texts to their peers. In line with this fact, the research question of the current study is defined as follows:

Q: Does presentation strategy have a significant effect on reading comprehension of Iranian Intermediate EFL learners?

Based on what the previous studies found on the effectiveness and usefulness of reading strategies in optimizing reading comprehension, this research tested the following hypothesis:

H0: Presentation strategy has no significant effect on reading comprehension of Iranian Intermediate EFL learners.

\section{Literature Review}

\subsection{Reading Comprehension}

Reading skill has always been viewed as critical to academic success (Levine, Ferenz, \& Reves, 2000; Grabe \& Stoller, Teaching and researching reading, 2002). To achieve this academic success, successful reading comprehension is regarded as an essential component of EFL/ESL learning. Reading comprehension is a continuous, complex, and interactive mental process between the readers and the texts, that is, between the readers' linguistic experiences, world knowledge, and topic knowledge. According to McNamara (2004) this interaction process involves synthesizing of linguistic knowledge from print, text-information building phase, and situation-model construction. This interaction can be further segmented into various levels, all of which occur simultaneously. Based on this viewpoint, reading comprehension levels include the word level, proposition level, local coherence level, macrostructural level, and superstructure level (Kintsch W. , 1998; Perfetti, 1994)

Reading comprehension research has a long history. Most of what we know about nature of reading comprehension dates back to 1975. According to Sweet and Snow (2002) constructing meaning from the contexts is one of the significant aims of reading comprehension. Thus, reading comprehension is meaning making process before, during and after reading by combining the data expressed in the text with the reader's prior knowledge (Sweet \& Snow 2002). Wilhelm and $\mathrm{Li}(2008)$ noted that "For most second language learners who are already literate a previous language, reading comprehension is primarily a matter of developing appropriate and efficient comprehension strategies" (p. 99).Researchers explored that readers need to use a large number of strategies in both reading and reading comprehension (Paris, Wasik, \& Turner, 1991), since in comprehension process readers should use different conscious and unconscious strategies to settle their difficulties (Johnston, 1983).

\subsection{Language Learning Strategies}

Strategies are considered as theoretical concepts put into practice. The American Heritage College Dictionary defines strategy as "a plan of action intended to accomplish a specific goal" (American Heritage College Dictionary, 1342). Therefore, strategy is goal driven. Joan Rubin is the first one who introduced and popularized Language Learning Strategies (LLS) in a paper named "What the 'Good Language Learner' Can Teach Us" in 1975. LLS are used to describe the conscious moves made by those learners decided to be effective in either learning or employing the target language. In educational process of a foreign or second language, LLS are regarded as an effective factor. Mokhtari and Richard (2002) stated that LLS can be defined as the specific techniques, behaviors and thoughts which learners employed to ease the acquisition, storage, and use of information. LLS are divided into different types including metacognitive strategies, cognitive strategies, performance strategies, and affective strategies. They are very different in nature. The examples of these strategies are ranged from deciding about the construction of one's learning (a metacognitive learning strategy) to repeating words mentally in order to unlock the meaning better if one is not certain about the meaning (cognitive learning strategies). The other categories involve rehearsing what one anticipates to quote which is a performance strategy and fostering one's self-confidence for a language task by means of self-talk which is regarded as an affective strategy.

As Ellis (1994) writes: "The study of learning strategies holds considerable promise both for language pedagogy and for explaining individual differences in second language learning. It is probably true to say, however, that it is still in its infancy. For this reason, perhaps, discussions of learning strategies typically conclude with the problems that have surfaced and that need to be addressed before progress can be made" (p. 558). Thus LLS help Learners take 
responsibility of their language learning and keep on their learning process even in the absence of teacher and classroom contexts. Therefore, strategies govern student-centered learning.

\subsection{Reading Comprehension Strategies}

The investigation of the various aspects of reading strategies received immense importance in the domain of reading research because of the critical role of the reading comprehension in first and second/foreign language academic contexts. A reading strategy can be identified as "a systematic plan consciously adopted and monitored to improve one's performance" in learning (Harris \& Hodges, 1995: 2 (Harris \& Hodges, 1995)44). A substantial body of research in the foreign language illustrated this fact that reading strategies guide students to better making sense of the printed texts. Brown (2001) noted that strategies regarded as the particular actions which learners use when encountered with some sorts of dilemmas. In this vein, reading strategies are helpful comprehension practices which readers use to understand the texts. According to Barnet (1989) and Kern (1989) there is a significant relationship existed between proficient and strategic reading and awareness of implementing proper strategies in reading texts. Advanced readers make use of strategies before, while, and after reading. The common point among these proficient readers is that comprehension strategies utilization assist them make sense of the written passages. The required knowledge for the purpose of realizing when, why, how, and where to employ strategies is vital to unlock the meaning of different texts with different levels of difficulty. Grabe (2009) suggested that a limited list of comprehension strategies includes comprehension monitoring, answering questions about what has been read, interactive learning, using graphic and semantic organizers, asking students make their own questions about the passages, activating background knowledge to connect the written materials to their previous experience, and summarizing the written tetxs. Skilled readers apply comprehension strategies without any instruction. They have automatically become aware in their use of these strategies.

\subsection{Types of Reading Strategies}

Various strategies are frequently utilized to read and understand a text. strategy types include fix-up strategies, predicting the meaning of a particular word from its context, summarizing, and integrating the read material to prior knowledge (Nunan, 1998). Oxford's (1990) Strategy Inventory for Language Learning (SILL) classifies strategies into the following classes: (1) direct strategy and (2) indirect strategy. Different kinds of direct and indirect strategies are applied in reading process whether in L1 or L2.

Memory, cognitive and compensation strategies are examples of direct strategies. Memory strategies make students acquire and store new information. Use of imagery and combining sounds and images are effective memory strategies in which readers can simply remind the written texts in the target language. On the other hand, Weinstein and Mayer (1986) suggested that cognitive strategies include a majority of actions that help learners govern behavior, emotion, motivation, communication, attention, and comprehension. Cognitive strategies have the capacity to enable students to make sense of the texts by different mechanisms. Looking for the meaning of vocabularies in the dictionaries is a cognitive strategy. This strategy makes use of the available sources to understand the text meanings, or to create messages. The instances of this type of strategy are note taking, summarizing and emphasizing important ideas. The other strategy is compensation strategy. Predicting meaning by implementing the existing linguistic signals is a particular kind of this strategy. It means that students point out the previously acquired knowledge of the second/foreign language, their own language or other languages that can create linguistic signals to the senses of the printed text.

On the other hand, indirect strategies advocate and handle reading in the absence of the target language. Indirect strategies are categorized into metacognitive, affective and social strategies. Monitoring one's speed and rate of reading is a metacognitive strategy. If the text contains high level of difficulty, readers gradually their speed of reading. Indeed, breathing deeply for the purpose of checking the anxiety level is an affective strategy. Asking for clarification, correction of errors, getting feedback and interacting with peers to better understanding of the passage or passages are social strategies.

\subsection{Reading Strategy Instruction}

Strategy-based teaching is a student-centered method to teaching with the aim of producing more indecency among learners and highlighting their proficiency levels. According to Brown (2001) it guides students become more aware of accessible strategies, to know how to organize and utilize strategies mechanically, and to learn when and how to transform the learned strategies to new contexts (Brown, 2001). Studies which have recently been done on the effectiveness of reading instruction have resulted into paramount improvements in the understanding of teaching strategies to students at various levels to become good readers. They demonstrated that explicit instruction of comprehension strategies results in extensive improvement in students' comprehension of new concepts and texts. According to Eskey (2005) good comprehension instruction involves both direct instruction in comprehension strategies and adequate time for actual reading, writing, and numerous debates of a text. Baker and Brown (1984) have substantiated this fact that proficient readers owe some effective comprehension strategies that they implement before, during, and after reading a text (Baker \& Brown, 1984). Furthermore, Wilhelm and Li (2008) signified that in order to understand texts "Effective readers appear to employ bottom-up processes, top-down processes, use of schema, and reader-text interaction" (p. 97). They noted that reading strategy instruction helps students to become effective in their strategy utilization (Wilhelm \& Li, 2008). Thus, EFL teachers should train their students to achieve a general understanding of the written text before probing the passage at various levels. 
Lots of other studies have thrived to strength enhanced metacognition and comprehension abilities through the explicit instruction of strategies. Wright and Brown (2006) examined the effectiveness of reading strategy instruction in raising the readers' awareness of reading strategies, in widening the number of strategies they applied and in stimulating learners to check their reading process. The results have indicated that strategy instruction could encourage readers to get feedback on their strategy use and appeared to foster their belief in their own reading skills and abilities (Wright \& Brown, 2006). Alsamadani in 2009 reported that despite the great importance of quality of reading strategies in better comprehension of texts, the quantity and number of applied reading strategies in reading does not lead to better understandings of texts. According to him instructors can train their students to use strategies of high quality not only to optimize their reading comprehension, but also to highlight awareness of their reading performance. EFL students should be trained to know how, when, and why to use strategies in certain contexts. Sheorey and Mokhtari (2001) state that "It is the combination of conscious awareness of the strategic reading processes and the actual utilization of reading strategies that distinguishes the skilled from the unskilled readers" (p. 433).

\subsection{Reading Strategy Use}

The association among strategy use knowledge and reading comprehension is dynamic and difficult. Since 1980s' numerous studies have been done based on the effectiveness of reading strategy use and reading comprehension progress (Jimenez, Garcia, \& Pearson, 1995; Anderson \& Roit, 1993).In an experimental study sheorey and Baboczky in 2008 explored the strategy use of college students. 545 Hungarian college students were enquired to self-rate their reading abilities in English on a particular scale from one to six. The obtained results showed that those students who rated themselves as excellent and efficient readers had a greater degree of mean on eight individual strategies and on the global strategies subscale. Second language reading is not simple for numerous language learners; the majority of learners require more time to improve their knowledge of strategy use for better reading comprehension performance in the target language. Thus, in line with this fact, researchers reveal that reading strategies are more significant than other elements such as vocabulary and grammar knowledge. Mokhtari and Sheorey (2002) argued that skilled learners appeared to use a wide range of strategies than less skilled language learners. They noted that the possible effects or results of understanding of the strategy use have considered of great importance. The current study focused on the use of presentation strategy for comprehension of reading process. Using presentation strategy, especially in today's classrooms, can be a huge advantage in trial. It is important to realize delivering effective presentations is dependent upon not only how students transfer information but how successfully they influence the whole class. Orally presentation of the passages assists students in comprehending and recalling of the texts effectively and creates selfconfident learners. In a research which has been conducted in 1977 Smiley, Oakley, Worthen, Campione, \& Brown examineda group of 367th grades proficient and less proficient readers. Based on the treatment procedure, they read one prose text and listened to a second one. They were tested orally for comprehension and remember of the text contents after considering it. Under both reading and listening situations, skilled readers remembered a greater proportion of the stories and poor readers remembered less quantity of the stories. Orally presentation of the reading texts was positively associated with the following listening performance. The findings revealed that less skilled readers have a usual comprehension problem and that listening and reading have similar comprehension similar processes (Smiley, Oakley, Worthen, Campione, \& Brown, 1977).

\subsection{The Models of Teaching Reading}

Three influential models are devised for explaining the reading process. These models are formulated based on foundational theories of learning. These theoretical processes include: bottom-up processes, top-down processes and interactive processes. The bottom-up model occurs at lower levels of sentences including letter- and word- level. This model suggests that those readers who use this model become proficient readers. Pressley in 2000 stated that readers who are successful and good at realizing the words become skilled readers whose proficiency is enhanced by their decoding ability. Accordingly, Pressley (2000) stated that fast or high speed decoding enhance reading comprehension. Various cognitive theories of reading impose different amount of concentration on the three approaches. Reading practitioners stress that the bottom-up approach concentrate on those required processes which readers employ to obtain necessary data from the printed materials. The advocators of these theories argue that readers handle letters and words in a through way (Gough, 1972).

On the other hand, top-down processing is recognized as information gathering based on the reader's background knowledge (Hinkel, 2002). The top-down model refers to a meaning-driven model where the learners' background knowledge helps them to create meaning from passage. Eskey (2005) argues that in the top-down model comprehension takes place from brain/mind to text and encompasses the entire reading process. On the other hand, Hedge (2000) pointed out that the top-down processing has been used to describe using of prior knowledge, intelligence, and experience to understand the meaning of a text. According to him, this kind of processing is used when readers interpret presuppositions and draw inferences. This model suggests that processing of massages begins in the mind of the readers with meaning-driven processes.

The most interesting model in describing the reading process is the interactive model. Grabe (1991) pointed out that this model takes into account different types of L1and L2 reading, considers both bottom-up processing and top-down processing, and recognizes its contribution to both the readers and the texts. The interactive model incorporates prior knowledge, guessing processes, and other overall reading processes, which do not exist in bottom-up models but exists in all aspects of top-down reading model. Furthermore, the interactive model reveals that (1) there is an interaction between the bottom-up and top-down processes and (2) bottom-up or top-down models cannot describe the entire 
reading process. Researches argued that teachers should regard employing both bottom-up and top-down processes according to students' requirements, skills, abilities, and levels. Through this method, reading instruction helps students understand that reading is an interaction between the readers and printed texts. Similarly, Rumelhardt (1977) states that "both sensory and nonsensory come together in one place and the reading process is the conclusion of simultaneous joint application of all the knowledge sources" (p. 735).

\section{Methodology}

The current researcher decided to examine the effect of presentation strategy on reading comprehension of Iranian intermediate EFL learners. A quantitative research method was utilized to consider the proposed research question of this research. For the purpose of having a good experimental design research in nature, internal threats to validity were monitored by administering of pretest to the subjects. To make sure that there were no significant difference among the students of both experimental and control groups considering the variables under investigation, a reading comprehension test as pre-test was administered to both classes at the outset of the treatment.

\subsection{Participants}

The participants of this study were selected from the students who enrolled in English Language Center of Chabahar Maritime University, Chabahar/ Iran. A total of 61 male and female students participated in the study and their age range was about 18-27 years old. Students were homogenized based on their obtained marks on TOEFL proficiency test administered to them prior to the experiment. They homogeneity was ensured as an intermediate level. The researcher randomly divided them into two experimental and control groups. Indeed, the target subjects were at the same level regarding the reading comprehension ability. It was assured based on their obtained scores in the reading comprehension pretest. As to the purpose of providing uniformity of instruction, the same teacher (the researcher) was assigned to train the students of both classes.

\subsection{Procedures}

The study took place in a period of ten weeks in 2013. By administering a standard TOEFL proficiency test, the intermediate level students were chosen as the target subjects of the study. Pre-test were conducted to both groups at the beginning of the academic term before the embarking of the experiment under the same administration procedure. The treatment procedure was assigned to experimental group after the pretest administration. The presentation strategy was fully practiced by the experimental group's students. The researcher first modeled the presentation strategy to the experimental group and assured that each student recognized how to employ it appropriately. In modeling process of the strategy, the students became acquainted with the following issues. First, students focused on important points of the printed passages. Second, they shared opinions considering the most interesting aspects of the passages. Third, students learned how to present the texts orally and become self-regulated and self-confident learners. Finally, the teacher provided students remarkable opportunities to ask questions about different sections of the passage and confer them with other classmates. These stages were thoroughly expounded and modeled to experimental group until the teacher was ensured that all students have accessed the required knowledge which is essential for the proper utilization of the presentation. Then at the beginning of each regular English class (three times a week, typically 45 minutes in duration) subjects used the target strategy before instructing the main book contents. The reading passages were taught in the first lesson and then the target subjects were assigned to present that particular passage for the next session. There were some sorts of discussions among students before, during, and after the presentation of the passages. Finally, they did the relevant exercises individually, in pairs or in small groups. And the recycle continued for each session until the end of the experiment. In the case of the control group, the researcher followed the usual approaches of teaching reading comprehension. The control group class started with discussing the title of the passage; focusing on main points of the passage and new vocabularies. The students read the passages silently. Then the teacher taught the passage using the other ordinary strategies and approaches including skimming, scanning, inferencing. Finally, they completed the exercises individually, in pairs or in small groups. The presentation strategy was worked for two weeks, three sessions in each week in 45 minutes, and then at the end of each two week instruction an immediate post-test was administered to both groups according to the strategy worked. Five immediate post-test were conducted for presentation strategy within ten weeks of instruction. Post-test data was collected at the end of the ten weeks instruction, i.e., at the end of the experiment.

\subsection{Data Analysis}

Statistical techniques used to analyze the obtained data in this study involve mean scores, Paired-sample t-test, and Independent sample t-test. The $21^{\text {st }}$ version of SPSS software was used for statistical analysis of the collected data from all of the research steps. The obtained results of data analyses confirmed the significant effect of presentation strategy on final reading examination scores of EFL students. In the first stage of the data analysis all the selected subjects were homogenized. A preliminary test for homogeneity of the experimental and control groups was administered to a total of 61 students bearing approximately the same background of English proficiency. The obtained scores were analyzed based on the performance of the subjects on TOEFL proficiency test. A reliable and valid way of choosing homogeneous groups of students is to consider the scores almost +1 and -1 standard deviation from the mean score. Then the researcher randomly divided them into two experimental and control groups. In order to have a more homogeneous group of students as to the main purpose of the current study, a reading comprehension pre-test was used to explore the homogeneity of the samples in terms of their reading proficiency. 


\section{Results}

Before considering the main research tests to answer the research question, descriptive statistics were calculated to achieve an overall understanding of the differences between the mean scores of the two groups. Table 1 and Table 2 shows that the mean of the pre-test scores of the control group was 26.33and the post-test score was 29.60. On the other hand, the mean of the pre-test scores of the experimental group was 27.54 and the mean of the post-test scores was 32.52.These statistics show that there was a significant difference between the mean scores of the two control and experimental groups at the end of the experiment.

Table1. Descriptive statistics for control and experimental groups' performance on reading comprehension pretest

\begin{tabular}{ccccc}
\hline Groups & Mean & N & Std. Deviation & Std. Error Mean \\
\hline Control & 26.33 & 30 & 9.001 & 1.679 \\
Experimental & 27.54 & 31 & 9.349 & 1.643 \\
\hline
\end{tabular}

Table 2. Descriptive statistics of the control and experimental groups' performance on reading comprehension posttest

\begin{tabular}{ccccc}
\hline Groups & Mean & $\mathrm{N}$ & Std. Deviation & Std. Error Mean \\
\hline Control & 30.60 & 30 & 8.789 & 1.741 \\
Experimental & 36.32 & 31 & 9.110 & 1.436 \\
\hline
\end{tabular}

As it can be seen in Table3, the reported sig. is $(P>.05) 0.826>.05$ which is larger than 0.05 . So there was no significant difference between these groups at the beginning of the experiment and they were comparable. Therefore, it can be claimed that any measurable changes in the posttests is not due to be the effect of differences between the two groups that exist at the start of the study and can be attributed to the different treatments and instructions that these groups encountered.

Table3. Test of homogeneity of Variances

\begin{tabular}{cll}
\hline Levene Statistic & df & Sig \\
\hline .171 & 82 & .826 \\
\hline
\end{tabular}

To investigate the significance of this difference and to answer the research question (Does presentation strategy have a significant effect on reading comprehension of Iranian intermediate EFL learners?), paired sample t-test was conducted to measure the effectiveness of presentation reading strategy on students' reading comprehension. To sum up the final results of the study, this study attempted to answer to this research question. The independent variable was presentation strategy, and the dependent variable deals with the students' obtained scores on a reading comprehension posttest given to them after they were trained and properly learned the independent variable of the study (presentation strategy). See table 4 for T-Test.

As for the phase of the statistical procedures, the researcher conducted Paired-samples t-test, because the variable to be tested was of the similar nature for both groups, that is, the reading skill. There exist some degrees of differences between the results of the pretest and posttest in both groups. This implies the fact that the significant difference between the experimental and control groups related to the improvement of their scores in reading skill. Table 7 represents the obtained $\mathrm{t}$ with the $\mathrm{P}$ value of 0.000 which is large enough to reject the hypothesis that there is a significant difference between the performances of the students in both classes in answering reading tests after overtaking a strategy based instruction and a traditional/ordinary- based (non-strategy based) instruction.

Table 4.Paired t-test comparing the performance of the experimental group on the reading comprehension pre- and post-tests

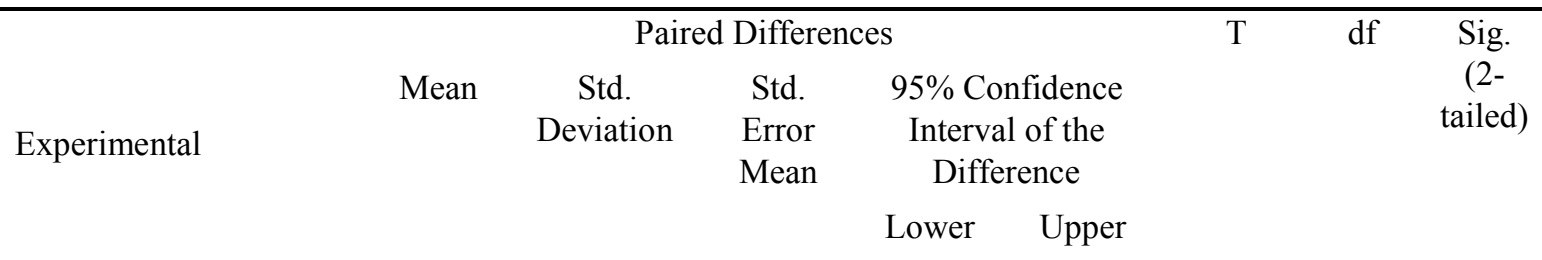

Pre-and post-test

$\begin{array}{lllllll}9.677 & 1.301 & .234 & -5.155 & -4.200 & 20.018 & 30\end{array}$


Table4 indicates that there is a significant difference between experimental and control groups in the post test. Since the level of significance is smaller than $0.05,0.000<0.05$.It means that experimental group significantly achieved superior results than the control group in the posttest.

A standardized reading comprehension posttest administered at the end of the term to capture the effectiveness of the used reading process. This means that students in experimental group (Presentation strategy group) had by far better performance in their reading skill than that of control group (non- strategy based/ordinary-based group). See table 5and Table 6 for paired samples correlations.

Table 5. Paired Samples Correlation

\begin{tabular}{cccc}
\hline Pair 1 & $\mathrm{N}$ & Correlation & Sig. \\
Reading Skill in Control Group & 30 & .63 & .041 \\
\hline
\end{tabular}

Table 6. Paired Sample Correlation

\begin{tabular}{cccc}
\hline Pair 1 & N & Correlation & Sig. \\
\hline Reading Skill in Experimental Group & 31 & .990 & .000 \\
\hline
\end{tabular}

Considering the data obtained in the above t-test tables, the findings of this study approved that first, presentation strategy was an effective and useful manner of preparation for reading text, and second, the differences in instructional method (non-strategy based vs. strategy-based instruction) were reflected in students' final reading comprehension test scores. The results of these statistical analyses confirmed the significant effect of presentation strategy on reading comprehension of Iranian intermediate EFL learners. It seems clear that the interpretations of these the research findings may be related to the efficiency of presentation strategy. The reason is that the experimental group's subjects took advantages of spending adequate time that the researcher gave them. This time span enabled them to use presentation strategy in better understanding of the passages. Findings of this study indicated that utilizing presentation strategy was useful for students. Even if they encountered many problems in the process, they learned a lot from solving their problems and taking responsibility for their own learning. Using presentation strategy helped the experimental group students of the current study to look at the strength and weaknesses of a particular reading passage and consider how to improve their weakness.

The results of this study entail the existing of some pedagogical implications. EFL teachers are satisfied to provide required time for students to cooperate with their classmates, express ideas, and show their understanding of the text individually or in groups. This discussion helps students to increase their comprehension awareness, assign their comprehension level, and correct their mistakes themselves.

\section{Discussion}

As it was revealed in the data, there was relationship between the degree of improvement of the reading comprehension ability and utilizing presentation strategy. In other words, the interesting point is that in general, the above results demonstrated that the changes in experimental group students' comprehension ability attributed to the use of presentation strategy during the treatment. One reason for the difference in comprehension of two groups could be related to the manners they approached the passages. Recently, presentation strategy has been used as a practical means of optimizing reading comprehension.

The theoretical and empirical findings of the previous studies supported the achieved findings of this study. The observed differences in the students' reading comprehension confirm the findings of previous studies which have substantiated that explicit reading strategy instruction promotes reading comprehension. Furthermore, the results indicated that presentation strategy helps students involved in text comprehend process by increasing both their cognitive and metacognitive monitoring skills. The experimental group's learners are given enough time to hesitate about their comprehension of the text before they began presenting the texts. In contrast, the control group's learners were trained to read the written passages based on the ordinary methods of teaching reading.

The motivation of this study was to provide the most interesting reading experience for English language learners. The instructional method which appeared to provide the best solutions to the students' problems was presentation strategy instruction. Implementing this way of teaching, the instructor assigned the target students to orally present the reading passage to the class. Students have had time to internalize instruction; this strategy authorizes students by passing them the chance to reread and overview their lectures before presenting their best and last attempt. The obtained results substantiated the students' progress, including the student's strengths and weaknesses as well as the student's achievements, efforts, and goals. Hence, the implementation of reading strategies including presentation one is a complementary possibility to traditional approaches of teaching reading for optimizing the effectiveness of reading strategy instruction. Since employing reading strategies provide a greater degree of student empowerment, with students able to continually improve their understanding of reading texts. The current study highlighted the fact that presentation strategy, as a technique of teaching reading, gives students a sense of greater control over their reading outcomes, and 
appears to contribute to increase their final scores on reading comprehension test. The data evidenced in the current study that presentation strategy can enhance the traditional approaches of teaching reading by reading effectively numerous reading passages and other related reading assignments. Presentation strategy provides not only a context for better comprehension but a focus on the enhancement of reading skills, namely organizing, presenting, and reflecting on learning. Presentation strategy affords teachers the opportunity to learn how students see themselves as readers and lecturers. One of the most positive aspects of using presentation strategy is its movement away from the teachercentered of teaching passages toward student-centered learning. The other cause of the students' success may be attributed to the fact that the conditional case of lecturing the text guide learners to obtain an overall picture of the text contents and its main topics. This position assists them to implicitly recognize the common constructions of the text. Having an overall picture of the text helps student to make sense of the passage better and make them to be more motivated and eager to read. On the whole, the findings of this study portrayed that comprehension skills can be enhanced by making use of appropriate strategies such as presentation strategy.

\section{Conclusion}

Reading comprehension can be regarded as one of the most important parts for a language learner to master and one of the least favorite choices for teachers to apply in the classroom. Hence, most of the students have difficulty with constructing meaning from the written texts. Therefore, as researchers conducted studies in the field of employing reading strategies, they found that reading strategy use is one of the main important factors to facilitate students' reading comprehension. It can be concluded that educational environments need to be actively improve various reading strategies including presentation strategy among all of the students. This study indicates that presentation strategy promotes both learners' reading comprehension and their reading performance. The current study further supports the claim that presentation strategy facilitates students' reading comprehension.

This study considers the view that explicit instruction of reading strategies is a flexible tool to enhance students' reading comprehension and benefited most from explicit reading instruction provided by practice in reading strategy activities. However, it may be challenging for instructors to practice reading strategy in the conventional way. Generally, it is important to note that after a relatively short time of reading comprehension instruction, students become self-regulated readers and they can be a proficient reader after finishing the strategy instruction learning. Then they know when and how to utilize strategy while reading. The mentioned strategy made students to take into account what they have learned and to process the existing information during the instruction. Besides, as students employ this strategy to their reading comprehension process, they systematically analyze information and ask questions according to the subject of the study.

The general findings of this study can be justified as follows: the first one is that less skilled readers do not utilize presentation strategy accurately and completely but skilled readers use frequently this strategy while reading texts. Second, readers who use presentation strategy in reading comprehension are more successful than those who do not utilize this strategy in comprehension process. Third, the general results indicated this study concentrate on the significance of utilizing reading strategies in education. The central achievement of the current study about the effect of presentation strategy instruction on EFL learners' reading comprehension ability is in the domain of the results of this study. It is implied that as reading strategies are in interaction in the teaching and learning process and influences on each other, we can achieve several goals by effectively learning a reading strategy. Thus, our students would be cognitively evolved processes, in which they gain the instruction. It is the responsibility of the teachers is to assure if their students recognize their own repertoire of learning strategies, and if not to instruct the strategies to obtain the aim of enhancing strategic learning of strategies.

\section{Acknowledgements}

The researcher would like to thank Dr.Khoshsima for his unfailing patience and insightful discussions.

\section{References}

Aghaei, R., \& Zhang, L. J. (2012). Effects of explicit instruction in cognitive and metacognitive reading strategies on Iranian EFL students' reading performance and strategy transfer. Instructional Science, 40(6), 1063-1081.

Akkakoson, S. (2012). Raising strategic awareness of Thai EFL students of science and technology disciplines through metacognitive strategy training. 3L; Language, Linguistics and Literature, The Southeast Asian Journal of English Language Studies, 18(4), 35-47.

Alderson, C. J. (2000). Assessing reading. Cambridge: Cambridge University Press.

Alfassi, M. (2004). Reading to learn: Effects of combined strategy instruction on high school students. The Journal of Educational Research, 97(4), 171-185.

Alsamadani, H. A. (2009). The Relationship between Saudi EFL College-Level Students' Use of Reading Strategies and Their EFL Reading Comprehension.Unpublished Doctoral Dissertation. Ohio University, OH.

Alsheikh, N. O., \& Mokhtari, K. (2011). An examination of the metacognitive reading strategies used by native speakers of Arabic when reading in English and Arabic. English Language Teaching, 4(2), 151-160.

Anderson, V., \& Roit, M. (1993). Planning and implementing collaborative strategy instruction for delayed readers in grades 6-10. The Elementary School Journal, 94(2), 121-137. doi:10.1086/461755 
Bagheri, Z. (2012). Teaching reading comprehension strategies to Iranian EFL pre-university students. The Journal pf Teaching Foreign Language Skills, 4(1), 107-138.

Bahmani, M. (2009). The use of meta-cognitive strategies among Iranian EFL learners with varying levels of proficiency in reading comprehension. Unpublished master's thesis, Urmia University, Urmia.

Barnett, M. A. (1989). More than meets the eye: Foreign language reading: Theory and practice. Englewood Cliffs: New Jersey: Prentice Hall Regents.

Bossers, J. (1992). Reading in two languages: A study of reading comprehension in Dutch as a second language and in Turkish as a first language. Rotterdam, The Netherlands: Drukkerij Van Driel.

Brown, D. H. (2001). Teaching by principles: An interactive approach to language pedagogy (2nd ed.). White Plains, NY: Addison Wesley Longman.

Carrell, P. L. (1991). Second language reading: Reading ability or language proficiency? Applied Linguistics, 159-179.

Carrell, P. L. (1998). Can reading strategies be successfully taught? The Language Teacher (Online), 22(3), 55 Paragraphs.

Chamot, A. U., \& O'Malley, M. J. (1994). Language learner and learning strategies. London: Academic Press.

Chang, K. E., Sung, Y., \& Chen, I. D. (2002). The effect of concept mapping to enhance text comprehension and summarization. The Journal of Experimental Education, 71(1), 5-23.

Cordero-Ponce, W. L. (2000). Summarization instruction: Effects on foreign language comprehension and summarization of expository texts. Reading and Instruction, 39(4), 329-350. doi:10.1080/19388070009558329

Duffy, G. G. (1993). Rethinking strategy instruction: Four teachers development and their low achievers understandings. The Elementary School Journal, 93(3), 231-247.

Ellis, R. (1994). The study of second language acquisition. Oxford: Oxford University Press.

Eskey, D. E. (2005). Reading in a second language. Mahvah, NJ: Erlbaum.

Eskey, F. (2005). Tech talk:Better English through reading in science and technology. University of Michigan Press.

Floyd, P., \& Carrell, P. L. (1987). Effects on ESL reading of teaching cultural content schemata. Language Learning, 37(1), 89-108. doi:10.1111/j.1467-1770.1968.tb01313.x

Gough, P. (1972). One second of reading. MIT Press, 331-358.

Grabe, W. (1991). Current developments in second language reading research. TESOL Quarterly, 25(3), 375-406. doi:10.2307/3586977

Grabe, W. (1991). Current developments in second language reading research. TESOL Quarterly.

Grabe, W. (2009). Reading in a second language: Moving from theory to practice. Cambridge: Cambridge University Press.

Grabe, W., \& Stoller, F. L. (2002). Teaching and Researching Reading (2nd ed.). Harlow: Pearson Education.

Harderback, J. (2006). Effectiveness and usage of reading comprehension strategies for second grade title 1 students. Unpublished Master Thesis.

Harris, T. L., \& Hodges, R. E. (1995). The literacy dictionary: The vocabulary of reading and writing. Newark, DE: International Reading Association.

Hedge, T. (2000). Teaching and learning in the language classroom. Oxford: Oxford University Press.

Hinkel, L. (2002). Handbook of research in second language teaching and learning. Taylor\& Francis.

Hong-Nam, K., \& Leavellm, G. L. (2007). A comparative study of language learning strategy use in EFL contexts: Monolingual Korean and bilingual Korean-Chinese university students. Asia Pacific Education Review, 8(1), 71-88.

Hosenfeld, C. (1977). A preliminary investigation of the reading strategies of successful and non-successful second language learner. System, 5, 110-123.

Huang, S. C. (2006). Reading English for academic purposes. What situational factors may motivate learners to read? System, 34, 371-383.

Jimenez, r. T., Garcia, G. E., \& Pearson, P. D. (1996). Three childeren, two languages, and strategic reading: Case studies in bilingual/monolingual reading. American Educational Research, 31(1), 90-112.

Jitendraa, A. K., Colea, C. L., Hoppesa, M. K., \& Wilsona, B. (2006). Effects of a direct instruction main summarization Program and self-monitoring on reading comprehension of middle school students with learning disabilities. System, 379-396. doi:10.1080/1057356980140403

Johnston, P. H. (1983). Reading comprehension assessment: A cognitive basis. New Jersey: International Reading Assossiation.

Kasper, L. F. (1993). The keyword method and foreign language vocabulary learning: A rational for its use. Foreign Language Annals, 26(2), 244-251. doi:10.1111/j.1944-9720.1993.tb01172.x 
Kern, R. G. (1989). Second language reading strategy instruction: its Effects on comprehension and word inference ability. Modern Language Journal, 73(2), 135-149. doi:10.1111/j.1540-4781.1989.tb02535.x

Khosravi, A. A. (2000). The Effect of scanning and skimming on the rate of and reading comprehension of Iranian EFL learners: Master Thesis.

Kintsch, W. (1998). Comprehension: A paradigm for cognition. Cambridge: Cambridge University Press.

Kintsch, W., \& van Dijk, T. A. (1978). Toward a model of text comprehension and production. Psychological Review, 85(5), 363-394.

Koda, K. (2005). Insights into Second Language Reading: A cross-Linguistic Approach. Cambridge: Cambridge University Press.

Lee, K. R. (2007). Strategy awareness-raising for success: Reading strategy instruction in the EFL context. Unpublished doctoral dissertation, University of Maryland, College Park. Retrieved from http://hdl.handle.net/1903/6859

Lems, K., Miller, L. D., \& Soro, T. M. (2010). Teaching Reading to English Language Learners: Insights from Applied Linguistics. New York: The Guilford Press.

Levine, A., Ferenz, O., \& Reves, T. (2000). EFL academic reading and modern technology: How can e turn our students into independent critica readers. TESL-EJ, 4(4), 134-142.

Maher Salah, S. (2008). The relationship between vocabulary knowledge and reading comprehension of athentic Arabic texts. Brigham Young University, 416-431.

Marzano, R. J., Pickering, d. J., \& Pollock, J. E. (2001). Classroom Instruction that Works: Research-Based Strategies for Increasing Students Achievement. New York: McREL.

McNamara, D. (2004). SERT: Self-explanation reading training. Discourse Processes, 38(1), 1-30. doi:10.1207/s15326950dp3801.1

Mokhtari, K., \& Reichard, C. (2004). Investigating the strategic reading processes of first and second language. System, 32(3), 379-394.

Mokhtari, K., \& Sheorey, R. (2002). Measuring ESL students' awareness of reading strategies. Journal of Educational Development, 25, 2-10.

Moreillon, J. (2007). Collaborative strategies for teaching reading comprehension. New York: American Library Association.

Morris, W. (1976). American heritage colledge dictionary.

Motallebzadeh, K., \& Mamdoodi, N. (2011). Language learning strategies: A key factor to improvement of TOEFL candidates' reading comprehension ability. International Journal of Linguistics, 3(1), 1-10.

Nambiar, R. (2009). Cross Linguistic Transfer Between L1 and L2 Texts: Learning Strategies Used by Bilingual Malay Tertiary Learners. European Journal of Social Science, 114-125.

Novak, J. D. (2010). Learning, creating, and using knowledge: Concept maps as facilitative tools in schools and corporations. Journal of e-Learning and Knowledge Society, 6(3), 21-30.

Nunan, D. (1998). Second Language Teaching and Learning. Harlow: Heinle and Heinle.

O'Malley, M. J., \& Chamot, A. U. (1990). Learning Strategies in Second Language Aquisition. Cambridge: Cambridge University Press.

Oxford, R. L. (1990). Language Learning Strategies: What Every Teacher Should Know. New York: Newbury House.

Palincsar, A. S. (1987). Metacognitive strategy instruction. Exceptional Childeren, 118-124.

Paris, S., Wasik, B. A., \& Turner, J. C. (1991). The development of strategic readers: Handbook of reading reseach. Mahwah, NJ: Lawrence Erlbaum.

Perfetti, C. A. (1994). Psycholinguistics and reading ability. Gernsbacher, Morton Ann (Ed): Handbook of Psycholinguistics, 849-894.

Phakiti, A. (2003). A closer look at gender and strategy use in L2 reading. Language Learning, 53(4), 649-702. doi:10.1046/j.1467-9922.2003.00239.x

Phakiti, A. (2006). Modeling cognitive and metacognitive strategies and their relationship to EFL reading test performance. Melborn Papers in Language Testing, 1, 53-95.

Pressley, M. (2000). What Should Comprehension Instruction Be The Instruction of? Handbook of Reading Research. Mahwah, New Jersey: Lawrence Erlbaum.

Rahmani, M. (2009). The effect of note-taking strategy training on reading comprehension and recall of Iranian EFL learners. Unpublished Master's Thesis, Urmia University, Iran, Urmia, 116-128.

Rausch, A. S. (2000). Language learning strategies instruction and language use applied to foreign language reading and writing: A simplified "menu" approach. Literacy Across Cultures, 4(1), 18-24. 
Richards, J. C., \& Renandya, W. A. (2002). Methodology in language teaching: An anthology of current cractice. Cambridge: Cambridge University Press.

Rivers, W. (1981). Teaching foreign language skills. Chicago: University of Chicago Press.

Rumelhart, D. (1977). Toward an interactive model of reading. School Effectiveness and School Improvement, 864 894.

Salataci, R., \& Akyel, A. (2002). Possible effects of strategy instruction on L1 and L2 reading. Reading in a Foreign Language, 14(1), 1-17.

Shang, H.-F. (2010). Reading strategy Use, self-efficacy, and EFL reading comprehension. Asian EFL Journal, 12(2), $18-42$.

sheorey, R., \& Baboczky, E. (2008). Metacognitive awareness of reading strategies among Hungarian college students. Reading Strategies of First-and Second-Language Learners, 161-173.

Sheorey, R., \& Mokhtari, K. (2001). Differences in metacognitive awareness of reading strategies among native and non-native readers. System, 29(4), 431-49. doi:10.1016/S0346-251X(01)00039-2

Shokrpour, N., \& Fotovatian, S. (2009). Effects of consciousness rising of metacognitive strategies on EFL students' reading comprehension. International Journal of Applied Linguistics, 157, 75-92.

Sleimani, H., \& Nabizadeh, F. (2012). The effect of learner constructed, fill in the map concept map technique, and summarizing strategy on Iranian pre-university students' reading comprehension. Canadian Center of Science and Education, 5(9), 78-87.

Smiley, S. S., Oakley, D. D., Worthen, D., Campione, J. C., \& Brown, A. L. (1977). Recall of thematically relevant material by adolescent good and poor readers as a function of written versus oral presentation. Journal of Educational Psychology, 69(4), 381-387.

Soleimani, H., \& Hajghani, S. (2013). The effect of teaching reading comprehension strategies on Iranian EFL Preuniversity students' reading comprehension ability. International Journal of Applied and Basic Sciences, 5(5), 594-600.

Sweet, A. P., \& Snow, C. (2002). Reconceptualizing reading comprehension. Improving Comprehension Instruction: Rethinking Research, Theory, and Classroom Practice, 17-53.

Taraban, e. a. (2004). Analytic and pragmatic factors in college students' metacognitive reading strategies. Reading Psychology, 67-81.

Tierney, R. J., \& Readence, J. E. (2005). Reading strategies and practices: A compendium. Boston: Pearson Education. Inc.

Weinstein, C. E., \& Mayer, D. K. (1986). The teaching of learning strategies: The handbook of research on teaching. New York: MacMillan.

Wilhelm, L. H., \& Harold, K. (2008). Exploring pedagogical reasoning: Reading strategy instruction from two teachers' perspectives. The Reading Matrix, 8(1), 96-110.

Wood, E., Motz, M., \& Willoughby, T. (1998). Examining students' retrospective memories of strategy. Journal of Educational Psychology, 90(4), 698-704. doi:10.1037/0022-0663.90.4.698

Wright, M., \& Brown, P. (2006). Reading in a modern foreign language: exploring the potential benefits of reading strategy instruction. Language Learning Journal, 33, 22-33.

Yau, J.-L. C. (2005). Two Mandarin readers in Taiwan: Characteristics of children with higher and lower reading proficiency levels. Journal of Research in Reading, 28(2), 108-123. 